\title{
RELACIÓN ENTRE LA NEMATOFAUNA Y LA HISTORIA DE MANEJO DEL SUELO EN HUERTOS FRUTÍCOLAS.
}

\section{RELATIONSHIP BETWEEN THE NEMATOFAUNA AND SOIL MANAGEMENT HISTORY IN FRUIT ORCHARDS.}

\author{
Claudia Azpilicueta ${ }^{1 *}$; María Cristina Aruani² y Eliseo Chaves ${ }^{3}$ \\ ${ }^{1}$ Laboratorio de Servicios Agrarios y Forestales- Ministerio de Desarrollo Territorial. Neuquén; \\ ${ }^{2}$ Facultad de Ciencias Agrarias - Universidad Nacional del Comahue (UNCo); ${ }^{3}$ Nemas Agris. Mar \\ del Plata. Argentina. \\ * Dirección de contacto: lasaf_suelos@ @neuquen.gov.ar. Santiago del Estero 426. (8300) Neuquén, \\ Argentina: 5402994483823.
}

\section{ABSTRACT}

Key words: Nematode community index, trophic group, medium textured soils.

The objective of this study was to differentiate sites influenced by long-term application of synthetic fertilizers, herbicides and tillage, using the percentages of nematode trophic groups and ecological indices on fruit orchards. The experiments were conducted in Upper Río Negro Valley, on medium texture soils. Seven sampling sites were established. Soil samples were collected in October, for two consecutive years. Main component analyses were performed. The distribution of the sites, according to the percentage of trophic groups (bacterivores, fungivores, plant feeders and omnivores-predators) and community indices of nematodes (MI, PPI, EI and SI) showed a different pattern of arrangement. Each long-term soil management supported different nematode assemblages. The plant-parasitic nematodes were the most abundant group in sites fertilized with nitrogen and under application of herbicide for at least ten years. The percentage of fungivore nematodes was higher in soils subjected to application of herbicides, no fertilizers and no tilling. Soils with a similar assemblage of nematodes, expressed in percentages of trophic group, did not necessarily presented a similar functional condition of the throphic web. The interpretation of the studied parameters can

\section{RESUMEN}

Palabras claves: Índices de la comunidad de nematodos, grupos tróficos, suelos textura media.

El objetivo del presente estudio fue evaluar sitios con diferente historial de fertilización, labranza y aplicación de herbicidas utilizando el análisis de grupos tróficos y los índices de la comunidad de nemátodos en huertos frutícolas. El estudio se realizó en el Alto Valle de Río Negro, en suelos de textura media. Las muestras de suelo fueron extraídas en octubre, durante dos años consecutivos. Los datos fueron explorados mediante análisis de componentes principales. La distribución de los suelos analizados, en función al porcentaje de grupos tróficos (bacteriófagos, fungívoros, fitófagos y omnívoros - predadores) y a los índices de la comunidad de nemátodos (IM, PPI, IE y IS) mostró distinto patrón de ordenamiento. Cada manejo de suelo a largo plazo presentó distintos ensambles de nemátodos. Los nemátodos fitófagos dominaron en suelos fertilizados con nitrógeno y aplicación de herbicidas durante 10 años. El porcentaje de nemátodos fungívoros fue mayor en suelos con aplicación de herbicidas, sin fertilizar y sin labranza. Los suelos con similar ensamble de grupos tróficos, expresado en porcentajes, no necesariamente presentaron similar condición funcional de la red trófica. La interpretación de los parámetros estudiados

Fecha recepción antecedentes: 17 de febrero 2012 
provide useful information about the nutritional status and ecological health of the soil in fruit orchards.

\section{INTRODUCCION}

En Argentina, la región Patagonia Norte concentra diversas economías productivas, cuenta con valles irrigados protegidos y con un clima apto para el desarrollo de frutales. Dentro de esta región, la provincia de Río Negro es la más importante productora a nivel nacional tanto de manzanas, cuya producción asciende a 910.000 toneladas $(69 \%$ de la producción nacional), como de peras, que alcanza las 630.000 toneladas $(75 \%$ de la producción nacional) (UIA, 2008). Los suelos son de origen aluvial y pobres en materia orgánica y el productor aplica anualmente fertilizante nitrogenado entre 100 a $200 \mathrm{~kg}$ ha-1, cifras consideradas elevadas para frutales de pepita que tienen menores requerimientos (Weinbaum et al. 1992). Otra práctica de manejo que se realiza anualmente es la labranza a comienzo del ciclo productivo para eliminar las malezas y luego se riega como método pasivo de lucha contra las heladas tardías.

Las prácticas de manejo como la labranza, fertilización, irrigación, aplicación de plaguicidas y herbicidas causan disturbios en el sistema suelo (Bongers et al., 1997) y afectan la estructura de la comunidad de nemátodos (Freckman y Ettema, 1993, Neher y Olson, 1999, Porazinska y Coleman, 1995, Villenave et al. 2010). La extensa literatura que existe sobre el comportamiento de poblaciones de nemátodos como bioindicadores de las alteraciones del suelo bajo distintas prácticas agrícolas, resalta el potencial que tienen estos animales para reflejar la situación en un agrosistema. Los nemátodos viven en el agua capilar y están en contacto directo con el microambiente debido a que tienen una cutícula permeable (Neher, 2001).

Los nemátodos constituyen uno de los componentes numéricamente más importantes de la fauna del suelo y ocupan posiciones claves en la red trófica del mismo, distribuyéndose de acuerdo a Yeates et al., (1993) en al menos cinco grupos funcionales: bacteriófagos, fitófagos, omnívoros, fungívoros y predadores. Bongers (1990) propuso varios índices para en esta investigación, puede proporcionar información útil sobre el estado nutricional y salud del suelo en huertos frutícolas. realizar un seguimiento de las condiciones del suelo y para ello, clasificó a las familias de nemátodos en una escala c-p (colonizadores a persistentes), resultando cinco grupos. Esta escala se utiliza para el cálculo del índice de madurez en nemátodos de vida libre (IM); se basa en el principio de que distintos taxa de nemátodos (excluyendo a los nematodos fitófagos) presentan diferente sensibilidad al estrés e indica la interrupción de la secuencia de la sucesión a causa de las diferencias en sus ciclos de vida (Bongers, 1990, 1999). Ferris et al., (2001) aumentaron la resolución del análisis de la nematofauna asignándole distinto peso a los grupos funcionales en relación al enriquecimiento y estructura de la red trófica del suelo, proponiendo los índices de enriquecimiento (IE) y de estructura (IS).

El objetivo del presente estudio fue evaluar sitios con diferente historial de fertilización, labranza y aplicación de herbicidas utilizando el análisis de grupos tróficos y los índices de la comunidad de nemátodos en huertos frutícolas.

\section{MATERIALES Y MÉTODOS}

\section{Descripción de los sitios}

Se seleccionaron siete sitios con similar textura implantados con frutales de pepita (manzano y peral), en el Alto Valle de Río Negro. Los suelos son de origen aluvial y están ubicados en la Terraza Aluvial Subreciente y pertenecen al orden Aridisol. El régimen de humedad corresponde al arídico y el de temperatura es térmico, lo que reflejan las condiciones de déficit hídrico durante todo el año (CIL, 1991). La temperatura media normal del mes más cálido (enero) es de $21,9^{\circ} \mathrm{C}$ y la más fría (julio) es de $5,7^{\circ} \mathrm{C}$ y la precipitación media anual de la región es de $224 \mathrm{~mm}$ (período 1972-2010 datos suministrados por la estación meteorológica Facultad de Ciencias Agrarias U.N. Comahue). Los suelos de los sitios 1, 2, 3, 4, 5 y 6 , son clasificados como Haplocambides típico y el suelo del sitio 7 es un Acuicambides típico (Soil Survey Staff, 2006). 
Cuadro 1: Descripción de cada sitio de suelo en la zona donde se realizó el muestreo. Table 1: Description of sites where sampling was conducted.

\begin{tabular}{|c|c|c|c|c|c|}
\hline Sitios & Ubicación & $\begin{array}{c}\text { Clase } \\
\text { Textrual }\end{array}$ & Cultivo & Fertilización - Labranza & $\begin{array}{l}\text { Control } \\
\text { maleza }\end{array}$ \\
\hline $\mathrm{S} 1$ & $\begin{array}{l}38^{\circ} 50^{\prime} 44^{\prime \prime} \mathrm{S} \\
68^{\circ} 04^{\prime} 12^{\prime \prime} \mathrm{O}\end{array}$ & $\begin{array}{l}\text { Franco } \\
\text { limoso }\end{array}$ & Manzano & 1998 a 2007 sin fertilizar + mínima labrnaza & Con guadaña \\
\hline $\mathrm{S} 2$ & $\begin{array}{l}38^{\circ} 50 ` 44^{\prime \prime} \mathrm{S} \\
68^{\circ} 04^{\prime} 12^{\prime \prime} \mathrm{O}\end{array}$ & $\begin{array}{l}\text { Franco } \\
\text { limoso }\end{array}$ & Manzano & $\begin{array}{l}1998 \text { a } 2004 \text { sin fertilizar + } 2004 \text { a } 2007 \text { fertilizado } \\
\text { con } 100 \mathrm{~kg} \mathrm{~N} \mathrm{ha}^{-1} \text { + mínima labranza }\end{array}$ & Con guadaña \\
\hline S3 & $\begin{array}{l}38^{\circ} 50 ` 44^{\prime \prime} \mathrm{S} \\
68^{\circ} 04^{\prime} 12^{\prime \prime} \mathrm{O}\end{array}$ & $\begin{array}{l}\text { Franco } \\
\text { limoso }\end{array}$ & Manzano & $\begin{array}{c}1998 \text { a } 2004 \text { sin fertilizar + } 2004 \text { a } 2007 \text { fertilizado } \\
\text { con } 200 \mathrm{~kg} \mathrm{~N} \mathrm{ha}^{-1} \text { + mínima labranza }\end{array}$ & Con guadaña \\
\hline $\mathrm{S} 4$ & $\begin{array}{l}39^{\circ} 01^{\prime} 28^{\prime \prime} \mathrm{S} \\
67^{\circ} 44^{\prime} 15^{\prime \prime} \mathrm{O}\end{array}$ & Franco & Manzano & $\begin{array}{l}1994 \text { a } 2004 \text { fertilizados con } 100 \mathrm{~kg} \mathrm{~N} \mathrm{ha}^{-1}+ \\
2004 \text { a } 2007 \text { sin fertilizar + sin labranza }\end{array}$ & Roundup \\
\hline S5 & $\begin{array}{l}39^{\circ} 01^{\prime} 28^{\prime \prime} \mathrm{S} \\
67^{\circ} 44^{\prime} 15^{\prime \prime} \mathrm{O}\end{array}$ & Franco & Manzano & $\begin{array}{c}1994 \text { a } 2004 \text { fertilizado con } 100 \mathrm{~kg} \mathrm{~N} \mathrm{ha}^{-1}+ \\
2004 \text { a } 2007 \text { fertilizado con } 75 \mathrm{~kg} \mathrm{~N} \text { ha- } 1+\text { sin labranza }\end{array}$ & Roundup \\
\hline S6 & $\begin{array}{l}39^{\circ} 01^{\prime} 28^{\prime \prime} \mathrm{S} \\
67^{\circ} 44^{\prime} 15^{\prime \prime} \mathrm{O}\end{array}$ & Franco & Manzano & $\begin{array}{l}1994 \text { a } 2004 \text { fertilizado con } 100 \mathrm{~kg} \mathrm{~N} \mathrm{ha}^{-1}+ \\
2004 \text { a } 2007 \text { fertilizado con } 150 \mathrm{~kg} \mathrm{~N} \mathrm{ha}^{-1}+\sin \text { labranza }\end{array}$ & Roundup \\
\hline S7 & $\begin{array}{l}38^{\circ} 05^{`} 55,3^{\prime \prime} \mathrm{S} \\
68^{\circ} 02^{`} 38,6^{\prime \prime} \mathrm{O}\end{array}$ & Franco & Peral & 1994 a 2009 sin fertilización y sin labranza & $\begin{array}{l}\text { Gramoxone } \\
\text { y Roundup }\end{array}$ \\
\hline
\end{tabular}

En el Cuadro 1 se precisa la localización geográfica y las prácticas de manejo de suelo realizadas en el lugar de extracción de las muestras de suelo de cada sitio. Estas prácticas son habituales para estos cultivos, en la zona frutícola del Alto Valle.

En los sitios fertilizados, el nitrógeno se aplicó en forma localizada, a ambos lados de la planta, en una franja de $20 \mathrm{~cm}$ de ancho ubicada a $50 \mathrm{~cm}$ del tronco. En los sitios 2 y 3, el nitrógeno se aplicó en dos momentos fenológicos: $50 \%$ en caída de pétalos y la otra mitad en cosecha. En el sitio 4, 5 y 6 el fertilizante se aplicó solamente en primavera, $50 \%$ en caída de pétalo y $50 \%$ en cuaje.

El sitio 7, fue elegido porque el lugar donde se extrajeron las muestras de suelo no fue fertilizado, ni labrado durante 15 años.

Los herbicidas fueron aplicados a razón de $400 \mathrm{~cm}^{3} / 100 \mathrm{~L}$ de agua, cinco veces por ciclo productivo, durante la historia del cultivo.

El sistema de riego gravitacional, a manto, fue por melgas sin pendiente y sin desagüe al pie y se realizaron siete riegos por ciclo productivo en los sitios 1, 2, 3 y 7 . El riego con microaspersores en los sitios 4, 5 y 6 se efectuó siguiendo un cálculo de demanda basado en la evapotranspiración del cultivo con la aplicación de un coeficiente según el estado fenológico de la planta equivalente a: crecimiento 0,6, maduración 1,26 y cosecha 0,85 (FAO, 2006).

El contenido de materia orgánico fluctuó entre 25-35 $\mathrm{g} \mathrm{kg}^{-1}$, magnitudes consideradas apropiadas para la zona (Aruani et al., 2001).

\section{Obtención de muestras y extracción de nemátodos}

Para el seguimiento de la nematofauna asociado a la rizósfera de manzano y peral, se tomaron muestras de suelo con un barreno de 5 $\mathrm{cm}^{2}$ de área y de 0 a $20 \mathrm{~cm}$ de profundidad, antes del comienzo del riego y la fertilización. Cada sitio estuvo conformado de tres repeticiones. Entre el 1 al 4 de octubre de 2005 y 2006, en los sitios: 1, 2, 3, 4, 5 y 6, se tomaron seis submuestras de suelo en la hilera de plantanción a $50 \mathrm{~cm}$ del tronco (hacia el interfilar) que conformaron una muestra compuesta. En el sitio 7 , la muestra compuesta, estaba conformada por 15 submuestras de suelo, extraída el 9 octubre de 2008 y 2009, en la fila de plantación, donde sólo se aplicó herbicida.

Las muestras de suelo fueron conservadas a $4{ }^{\circ} \mathrm{C}$ hasta su procesamiento, en un período menor a siete días. Para la extracción de los nemátodos se separó una alícuota de $100 \mathrm{~cm}^{3} \mathrm{de}$ cada muestra de suelo húmedo, se homogeneizó manualmente y se procesó mediante la técnica de flotación - centrifugación (Caveness y Jensen, 1955). Todos los nemátodos de una alícuota de $4 \mathrm{~mL}$ de una solución $14 \mathrm{~mL}$ fueron identificados y contados utilizando un microscopio óptico. Luego se estimó la abundancia de nemátodos teniendo en cuenta el volumen total de la solución. La densidad de nemátodos fue expresada en peso de suelo seco y para ello se determinó la humedad del suelo de cada muestra gravimétricamente secando a $105^{\circ} \mathrm{C}$ hasta peso constante. 
Cuadro 2: Porcentaje de grupo tróficos de nemátodos de cada sitio.

Table 2: Percentage of nematode trophic groups of each site.

\begin{tabular}{lrrrrrrr}
\hline $\begin{array}{l}\text { Grupos tróficos } \\
(\%)^{* *}\end{array}$ & S1 & \multicolumn{1}{c}{ S2 } & \multicolumn{1}{c}{ S3 } & S4 & S5 & S6 & S7 \\
\hline B & 37,6 & 43,3 & 36,8 & 7,2 & 9,5 & 15,3 & 29,3 \\
$\mathrm{Fu}$ & 5,0 & 6,5 & 4,9 & 3,8 & 2,8 & 1,5 & 24,9 \\
$\mathrm{Fi}$ & 44,9 & 36,0 & 47,6 & 86,7 & 83,9 & 81,1 & 40,1 \\
O-P & 12,5 & 14,2 & 10,7 & 2,5 & 3,8 & 2,1 & 5,6 \\
\hline
\end{tabular}

* Cada sitio tiene 3 repeticiones

** B: Bacteriófagos, Fi: Fitófagos, Fu: Fungívoros, O-P: Omnívoros - Predadores.

\section{Comunidad de nemátodos}

Los taxones de nemátodos fueron asignados a los siguientes grupos tróficos: bacteriófagos (B), fungívoros (Fu), fitófagos (Fi) y omnívoros - predadores (O-P) de acuerdo a Yeates et al., (1993). Se determinó la abundancia y porcentaje de cada grupo trófico. Los taxa de nemátodos fitófagos fueron asignados como fitófagos obligados y facultativos, ya que existe evidencia de que algunos miembros de la familia Tylenchidae, como por ejemplo Filenchus también se alimentan y se reproducen sobre hifas (Okada et al., 2005), por ello se los ubicó como fitófagos facultativos.

El índice de madurez (IM) para nemátodos de vida libre se calculó como $I M=\sum v_{i} * f_{i}$ donde $f_{i}$ es la frecuencia de la familia $i$ en la muestra y $v$ es el valor c-p asignada a la familia $i$ (Bongers, 1990; Bongers y Bongers, 1998). El índice PPI, se calculó igual que el índice IM pero solamente con nematodos fitoparásitos (Bongers, 1990). La relación PPI/IM (índice de madurez de nemátodos fitoparásitos sobre el índice de madurez de nemátodos de vida libre) se analizó como indicador del estado nutricional del suelo (Bongers et al., 1997). El índice de enriquecimiento (IE) y el índice de estructura (IS) fueron determinados de acuerdo a Ferris $e t$ al., (2001). Se calculó el componente basal $b$ de la red trófica (grupos de nemátodos fungívoros y bacteriófagos incluidos como c-p $=2$ ) como $b$ $=\sum k_{b} n_{b}$ donde $k_{b}$ es la constante ponderada para el grupo y $n$ es el número de nematodos en ese grupo. Los componentes de enriquecimiento $(e)$ y de estructura $(s)$ se calcularon de la misma manera, utilizando los grupos indicativos de enriquecimiento (bacteriófagos con valor de $\mathrm{c}-\mathrm{p}=1(\mathrm{Ba} 1)$ y fungívoros con c-p $=2(\mathrm{Fu} 2))$ y aquellos grupos que están relacionados con la estructura de la red trófica (bacteriófagos con valor de $\mathrm{c}-\mathrm{p}=3-5$, fungívoros con $\mathrm{c}-\mathrm{p}=3-5$, omnívoros con $\mathrm{c}-\mathrm{p}=3-5$ y predadores con $\mathrm{c}-\mathrm{p}=$ 2-5). El índice IE fue calculado como $100 \times(e /$ $(e+b))$ y el índice IS como $100 x(s /(s+b))$.

\section{Análisis estadístico}

El estudio del porcentaje de los grupos tróficos y de los índices de la comunidad de nemátodos se realizó mediante el análisis multivariado de componentes principales (ACP) con los datos de dos años de observación consecutivos. Se interpretaron los dos primeros componentes (CP1 y CP2) considerándose las correlaciones mayores a 0,5 entre cada componente principal y las variables originales, utilizando el programa Infostat (Di Rienzo et al., 2009).

\section{RESULTADOS}

Los cuatro grupos tróficos de nemátodos estuvieron representados en todos los suelos (Cuadro 2) cultivados con frutales de pepita.

En el análisis de componentes principales de los porcentajes de los grupos tróficos de nemátodos se observó que los dos primeros, CP1 y CP2, explican el $99 \%$ de la variabilidad del sistema (Figura 1). Según el CP1 los sitios se distribuyeron en función a los porcentajes de nemátodos bacteriófagos, fitófagos y omnívoros - predadores y según la CP2 en relación al porcentaje de nemátodos fungívoros (Cuadro 3).

A partir del biplot (Figura 1) se conformaron dos grupos de suelo y el sitio S7 quedó aislado. En los suelos del grupo 1 (G1), conformado por los sitios S1, S2 y S3, dominaron los nemátodos bacteriófagos y fitófagos (39,2 y 42,8 \%, respectivamente), mientras que en los suelos 


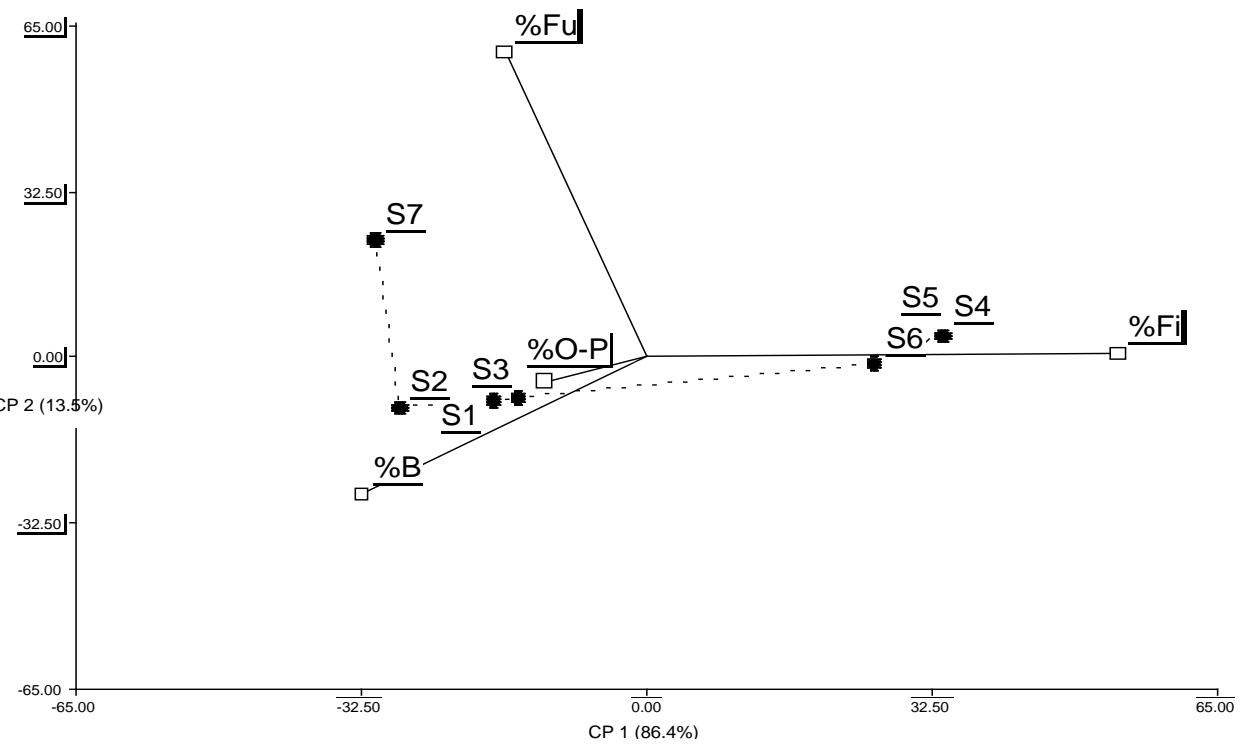

Figura 1: Biplot de los sitios de suelo y porcentaje de cada grupo trófico de nemátodos. Figure 1: Biplot of soil sites and percentages of nematode trophic groups.

: Grupos tróficos de nematodos B: Bacteriófagos, Fi: Fitófagos, Fu: Fungívoros, O-P: Omnívoros - Predadores. : Sitios. Línea discontinua entre sitios: árbol de recorrido mínimo.

del grupo 2 (G2: sitios 4, 5 y 6), los nemátodos fitófagos fueron los predominantes $(83,9 \%)$. El suelo del sitio 7 , presentó la mayor diversidad trófica (Cuadro 2).

La abundancia media de los nemátodos fitófagos obligados fue mayor que la de los nemátodos facultativos en los suelos de G1 y G2, a diferencia de lo que se obtuvo en el S7 (Cuadro 4). En el cuadro 5 se detalla la abundancia media de los taxones que corresponden a nemátodos fitófagos obligados y facultativos.

Los índices de la comunidad de nemátodos

Cuadro 3: Correlación entre las componentes principales (CP) y los grupos tróficos de nemátodos. Table 3: Correlation between principal main components (CP) and nematode trophic groups.

\begin{tabular}{lrr}
\hline Variables & CP1 & CP2 \\
\hline $\mathrm{B}$ & $-0,53$ & $-0,32$ \\
$\mathrm{Fu}$ & $-0,32$ & 0,92 \\
$\mathrm{Fi}$ & 0,56 & 0,01 \\
$\mathrm{O}-\mathrm{P}$ & $-0,55$ & $-0,19$ \\
\hline
\end{tabular}

B: Bacteriófago, Fi: Fitófagos, Fu: Fungívoros, O-P: Omnívoros - Predadores. fueron ordenados en dos dimensiones (Figura 2) de acuerdo al ACP. Los índices IM y PPI estuvieron correlacionados con la CP1 (Cuadro 6) que explicó el $52,7 \%$ de la variabilidad mientras que el índice IE se correlacionó con el segundo componente que explicó el 25,5\% de la variabilidad. El índice IS contribuyó de igual manera en la formación de las CP1 y CP2. A partir de la distribución de los sitios en el plano principal (Figura 2) se conformó un grupo (G3) que incluye a los suelos de los sitios 1, 2, 3, 4 y 5 y los sitios 6 y 7 quedaron aislados. En el Cuadro 7 se detallan los valores medios de las variables de cada grupo.

La densidad media de nemátodos oportunistas de enriquecimiento, bacteriófagos (c-p1) mas fungívoros (Fu2), fue mayor en G3 y S6 que en S7 (Figura 3).

\section{DISCUSION}

La distribución de los suelos analizados, en función al porcentaje de grupos tróficos y a los índices de la comunidad de nemátodos mostró distinto patrón de ordenamiento.

Dong et al., (2008) encontraron que el ajuste 


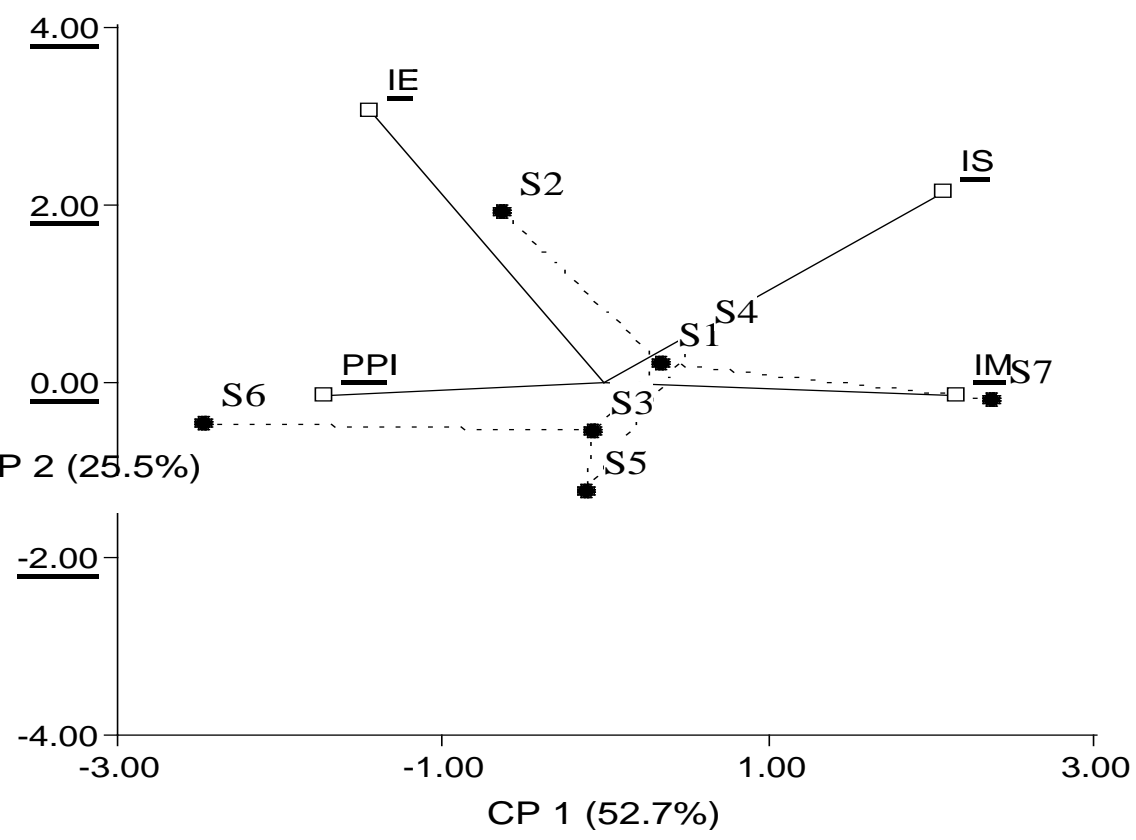

Figura 2: Biplot de los sitios de suelo y los índices de la comunidad de nemátodos. Figure 2: Biplot of soil sites and nematode community indices.

Índice IM: índice de madurez de nematodos de vida libre, PPI: índice de madurez de nematodos fitoparásitos, IE: índice de enriquecimiento, IS: índice de estructura. G3: Grupo 3. _: sitios. Línea discontinua entre sitios: árbol de recorrido mínimo.

del perfil de los grupos tróficos de nemátodos pudo dilucidar diferentes manejos del suelo. En este estudio, la conformación de los siete sitios en el plano principal, en función a los porcentajes de los grupos tróficos, reveló distintas prácticas de manejo agrícolas, ordenándose los suelos en G1, G2 y S7. Los suelos de los sitios de cada grupo tienen en común prácticas de manejo a largo plazo, ya que G1 permaneció sin fertilizar y sin herbicida durante seis años y G2 fue fertilizado con $100 \mathrm{~kg} \mathrm{ha}^{-1}$ de nitrógeno y con aplicación de herbicida durante 10 años, aunque recibieron distintas prácticas a corto plazo. En G1, la estructura trófica de nemátodos fue similar en los suelos sin fertilizar (S1) y en aquellos que fueron fertilizados durante tres ciclos productivos, con dosis de 100 (S2) y 200 (S3) $\mathrm{kg} \mathrm{ha}^{-1}$ de nitrógeno y no recibieron herbicida. En el G2, los suelos S5 y S6 que recibieron tres años de fertilización nitrogenada 75 y 150 $\mathrm{kg} \mathrm{ha}^{-1}$, respectivamente, se agruparon con el S4 que se dejó de fertilizar durante esos años y que coincidentemente recibieron aplicación de Roundup (Cuadro 1). La organización de

Cuadro 4: Abundancia media de nemátodos fitófagos obligados y facultativos / $100 \mathrm{~g}$ de suelo seco en cada grupo de suelo.

Table 4: Average number of obligatory and facultative plant-parasitic nematodes / $100 \mathrm{~g}$ dry soil in each soil group.

\begin{tabular}{lccc}
\hline $\begin{array}{l}\text { Nemátodos } \\
\text { fitófagos }\end{array}$ & G1 (S1,S2,S3) & $\begin{array}{c}\text { Grupos de suelo } \\
\text { G2 (S4, S5, S6) }\end{array}$ & S7 \\
\hline Obligados & 42 & 301 & 14 \\
Facultativos & 27 & 20 & 34 \\
\hline
\end{tabular}


Cuadro 5: Abundancia media de nemátodos fitoparásitos / 100 g de suelo seco en cada sitio. Table 5: .Average number of plant-parasitic nematodes / $100 \mathrm{~g}$ dry soil in each site.

\begin{tabular}{lrrrrrrr}
\hline \multicolumn{1}{c}{ Taxones ** } & \multicolumn{9}{c}{ G1 } & Sitios * & G2 & S7 \\
& S1 & S2 & S3 & S4 & S5 & S6 & \\
\hline Criconematidae (FiO) & 5,9 & 15,8 & 4,9 & 7,0 & 6,0 & 0,0 & 1,3 \\
Helicotylenchus (FiO) & 1,5 & 0,3 & 2,5 & 0,0 & 0,2 & 0,5 & 5,3 \\
Hemicycliophora (FiO) & 2,6 & 10,5 & 7,0 & 296,0 & 220,0 & 185,0 & 0,0 \\
Paratylenchidae (FiO) & 2.0 & 2,5 & 3,7 & 15,5 & 10,0 & 3,0 & 0,0 \\
Pratylenchus (FiO) & 30,0 & 16,0 & 17,7 & 43,5 & 46,0 & 46,0 & 4,8 \\
Tylenchidae (FiF) & 32,5 & 22,0 & 28,3 & 19,0 & 15,0 & 26,0 & 34,0 \\
Xiphinema (FiO) & 0,0 & 0,0 & 0,0 & 0,0 & 0,0 & 0,0 & 2,2 \\
\hline
\end{tabular}

*Corresponde a tres repeticiones por sitio.

** FiO: nemátodos fitófagos obligados; FiF: nemátodos fitófagos facultativos

los ensambles biológicos depende de variables físicas y químicas que definen las propiedades del sistema (Sánchez-Moreno et al., 2006) como por ejemplo cambios en el manejo del suelo conducen a diferentes comunidades (Sánchez-Moreno et al., 2007). En este estudio, el análisis de los sitios con manejo de suelo a corto plazo, no manifestó suficiente cambio en la distribución del porcentaje de grupos tróficos de nemátodos de la situación de manejo a largo plazo. Por ejemplo, los sitios S2 y S3 en G1 y los sitios S4 y S6 en G2, con manejo a corto plazo, se agruparon con los sitios que mantuvieron prácticamente el mismo manejo a largo plazo, como S1 en G1 y S5 en G2. Otros ensayos con fertilizantes en el mismo $\mathrm{u}$ otros cultivos, en la misma u otras zonas, confirmaron que los cambios más significativos en la estructura de la comunidad de nemátodos se dieron a partir del segundo al sexto año y que la comunidad de nemátodos se estabilizó con cambios mínimos a partir del séptimo al noveno año, considerando el mismo manejo (Gruzdeva et al., 2007).

Cuadro 6: Correlación entre las componentes principales (CP) y los índices de la comunidad de nemátodos.

Table 6: Correlation between main components (CP) and nematode community indices.

\begin{tabular}{ccc}
\hline Variables & CP1 & CP2 \\
\hline IM & 0,58 & $-0,04$ \\
PPI & $-0,50$ & $-0,04$ \\
IE & $-0,39$ & 0,82 \\
IS & 0,56 & 0,57 \\
\hline
\end{tabular}

IM: índice de madurez de nemátodos de vida libre, PPI: índice de madurez de nemátodos fitoparásitos, IE: índice de enriquecimiento, IS: índice de estructura.
El caso del S7, el porcentaje de nemátodos fungívoros fue mayor que en los otros grupos de suelo (Cuadro 2) siendo el porcentaje similar al de los nemátodos bacteriófagos. En los sistemas agrícolas, esta categoría trófica es una de las menos representada, respecto a los nematodos bacteriófagos y fitófagos (Wasilewska, 1979). Freckman y Ettema (1993), encontraron, en segundo lugar de abundancia, a los nemátodos fungívoros después de los bacteriófagos, en suelos no labrados. La presencia de este grupo es de gran importancia ya que en la fila de plantación, donde no recibió fertilización nitrogenada ni fue labrado, la acción de los fungívoros colaboraría junto con los bacteriófagos, en la nutrición de la planta. Probablemente esto también ocurra en el suelo de la fila plantación de los otros sitios donde no se aplica fertilizante ni se labra. Se sabe que los nemátodos que se alimentan de hongos o de bacterias, así como otros organismos que se alimentan de descomponedores primarios, aceleran la descomposición de la materia orgánica del suelo y liberan nutrientes para el crecimiento de las plantas, ya que asimilan mas nitrógeno de lo necesario excretando el exceso como amonio (Neher, 2001). La participación de los nemátodos fungívoros está asociada con la acumulación de residuos de las plantas en la superficie del suelo, que promueven el desarrollo de hongos y conduce a una red trófica más balanceada de hongos y bacterias (Hendrix et al.,1986).

Los suelos con mínima labranza fertilizados o sin fertilizar (G1), presentaron los porcentajes más altos de nemátodos bacteriófagos. Las redes tróficas basadas en bacterias tienen velocidades 


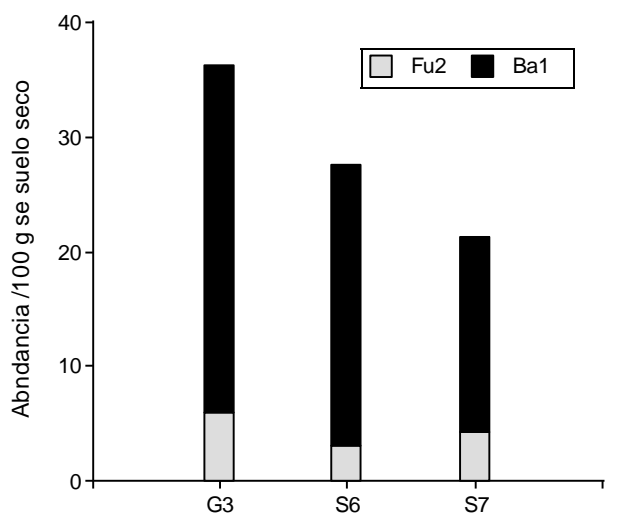

Ba1: nemátodos bacteriófagos c-p1; Fu2: nemátodos fungívoros c-p2.

Figura 3: Abundancia media de nemátodos oportunistas de enriquecimiento (Ba1 + Fu2) / 100 g de suelo seco.

Figure 3:Average number of enrichment opportunist nematodes (Ba1 + Fu2) / 100 g dry soil.

Ba1: nemátodos bacteriófagos c-p1; Fu2: nemátodos fungívoros c-p2.

de descomposición más altas que las basadas en los hongos (Porazinska y Coleman, 1995). El enriquecimiento con nitrógeno y la labranza favorecen las rutas de descomposición dominada por bacterias (Lenz y Eisenbeis, 2000).

La disminución en la diversidad trófica observada en los suelos de S4, S5 y S6 del G2 (Cuadro 2), donde predominaron los nemátodos fitófagos, puede deberse al manejo intensivo del suelo (Yeates y Bongers, 1999). La abundancia de este grupo está asociada con una mayor biomasa radical, probablemente debido al efecto del fertilizante nitrogenado (Van Eckeren et al., 2009). Cabe mencionar, que el sistema radical es un factor biótico importante que afecta la abundancia de los nemátodos fitófagos del suelo, siendo la dinámica de la planta la que regula la actividad de estos nemátodos (Norton, 1989). En G2, predominaron los nemátodos fitófagos obligados, siendo Hemicycliophora el género dominante y en G1 Pratylenchus (Cuadro 5). Villenave et al., (2010) observaron en sorgo, que el número de nemátodos fitófagos aumentó al agregar urea y estiércol, sugiriendo que la adición a largo plazo de urea podría incrementar más los nemátodos fitófagos, pero no permite que se mantenga el contenido de $\mathrm{C}$ en el suelo. Los mismos autores señalan que el agregado de estiércol, si bien aumenta la densidad de nemátodos fitófagos, también aumenta el número de nemátodos bacteriófagos y fungívoros indirectamente, por tener una fuente de C. En los suelos de S7, el porcentaje de fitófagos, fue de 40,1\% similar a los valores

Cuadro 7: Valores medios ( \pm DS) de los índices de la comunidad de nemátodos de cada grupo de suelo. Table 7: Mean values $( \pm$ SD) of community nematode indices of each group of soil.

\begin{tabular}{cccc}
\hline Índices & \multicolumn{3}{c}{ Grupos de suelo } \\
& G3 (S1,2,3,4,5) & Sitio 6 & \multicolumn{1}{c}{ Sitio 7 } \\
\hline IM & $2,37 \pm 0,4$ & $1,98 \pm 0,4$ & $2,61 \pm 0,3$ \\
PPI & $2,69 \pm 0,2$ & $2,89 \pm 0,1$ & $2,33 \pm 0,2$ \\
IE & $68,57 \pm 12,9$ & $71,62 \pm 19,4$ & $59,12 \pm 9,4$ \\
IS & $74,89 \pm 14,4$ & $52,26 \pm 23,0$ & $88,62 \pm 8,7$ \\
\hline
\end{tabular}

IM: índice de madurez de nematodos de vida libre, PPI: índice de madurez de nematodos fitoparásitos, IE: índice de enriquecimiento, IS: índice de estructura 
en los suelos de G1, la población en S7 estuvo integrada en su mayoría por nemátodos de la familia Tylenchidae (Cuadro 5). Este taxón está conformado por numerosas especies de las cuales no se conoce completamente sus hábitos alimenticios, aunque existen evidencias que algunas especies se reproducen cuando se alimentan de hongos (Okada et al., 2005).

El porcentaje de nemátodos omnívoros predadores fue alto en los suelos G1 y S7, respecto a $\mathrm{G} 2$ y a otras investigaciones, donde representaron un 2,6\% de la comunidad de nemátodos en suelos con cultivos perennes (Freckman y Ettema, 1993, Ferris et al., 1996). Estos nemátodos constituyen los niveles tróficos más altos entre la microfauna (Wasilewska, 1997) y son sensibles a disturbios del suelo (Bongers, 1999). La disminución o ausencia de esta categoría podría indicar deterioro en la salud del suelo porque juegan un rol clave en la mineralización de nutrientes (Wang et al., 2006) y tienen un efecto regulatorio sobre la abundancia de especies oportunistas. En ausencia de estos reguladores, los fitófagos pueden aumentar de manera descontrolada y reducir la producción autotrófica (Ferris, 2010).

Estos resultados observados a principio de primavera coinciden con uno de los dos momentos de crecimiento de las raíces de los frutales de pepita (Sánchez, 1999), donde se requiere de una buena condición nutricional del suelo, ya que la planta no solo utiliza los nutrientes de reserva sino también los absorbe del suelo.

A partir del análisis de los índices de la comunidad de nemátodos, los suelos se distribuyeron en el plano principal en G3, integrado por los sitios 1, 2, 3, 4 y 5, y dos sitios aislados S6 y S7 (Figura 2, Cuadro 7). El índice de madurez (IM) puede variar con las prácticas de manejo, la clase textural del suelo, el cultivo y la estación del año (Neher, 1999). Valores de IM más pequeños indican un ambiente más disturbado que valores mayores (Bongers, 1990). Los suelos del sitio 7 , que únicamente recibieron herbicidas a largo plazo, fueron los menos perturbados. Algunas evidencias sostienen que la aplicación de herbicidas no tuvo un efecto detrimental sobre la densidad poblacional de nemátodos (Yeates et al., 1999). Bajo la influencia de la fertilización nitrogenada, el IM disminuye a causa de una mayor actividad microbiana (Bongers y Bongers, 1998), lo cual involucra a la mayoría de los suelos de G3 y a S6. Cabe destacar que si bien en el S1, no se agregó fertilizante químico, recibió aportes orgánicos de la vegetación espontánea como el S2 y S3 y mínima labranza en la zona donde se extrajeron las muestras de suelo y el sitio 4 que no se fertilizó durante los últimos tres años, proviene de una historia de 10 años de fertilización. Esta información del índice IM se complementa con la interpretación del índice de enriquecimiento (IE) que refleja la respuesta que tienen algunos taxa de nemátodos al aumentar el recurso disponible (Ferris et al., 2001). El grupo G3 y S6 con valores de IE altos y mayores respecto al sitio 7, presentaron mayor abundancia de nemátodos oportunistas de enriquecimiento, tales como los bacteriófgos c-p1 (Ba1) más los fungívoros c-p2 (Fu2) (Figura 3).

La fertilización y/o labranza provocan un aumento sobre los nemátodos oportunistas de enriquecimiento que puede enmascarar los cambios en la complejidad estructural de la comunidad de nemátodos (Bongers, 1999), que se interpreta a través del índice de estructura (IS) (Ferris et al., 2001). En este ensayo, los valores más altos de IS correspondieron a los suelos de G3 y S7, el primer grupo incluye suelos no fertilizados con mínima labranza, suelos fertilizados solo durante tres años y suelos fertilizados tres años con una dosis menor a la que recibió durante 10 años. Los valores de IS altos indicarían redes tróficas más estructuradas y/o más complejas por lo cual se espera que sean más estables y que contengan probablemente nemátodos omnívoros, predadores junto con otros componentes de la red trófica del suelo, que pueden reducir poblaciones de patógenos o parásitos de plantas (Sánchez-Moreno y Ferris, 2007), debido a que habría más uniones en la red trófica y más interacciones entre organismos (Ferris et al., 2004).

Redes tróficas más complejas (IS alto) pueden coexistir con nemátodos oportunistas de enriquecimiento (IE alto), situación que se refleja en los suelos de G3 (Cuadro 7). Esto indica que la presencia de nemátodos de niveles tróficos más altos, como omnívoros y predadores, pueden sobrevivir en suelos enriquecidos. Estos resultados coinciden con las observaciones realizadas por otros investigadores en cultivos perennes (Ferris et al., 2001, Sánchez-Moreno et al., 2006). El sitio 7, si bien presenta una red 
trófica estructurada y compleja, su índice de enriquecimiento es el más bajo, lo que revela menor abundancia de nemátodos oportunistas (Figura 3), entre ellos los nemátodos Ba1 que están asociados con la descomposición rápida de la materia orgánica sumado a los nemátodos Fu2 que están relacionados. Algunos índices de la comunidad de nemátodos (IS, IE) son insensibles a los cambios en los agrosistemas debido a que los fitófagos pueden encontrarse en una proporción muy alta; como este grupo trófico no está incluido en los cálculos de los índicesinterpretados anteriormente (Berkelmans et al., 2003), se utilizó el índice de madurez de nemátodos fitoparásitos (PPI). Bongers et al., (1997), encontraron una relación positiva entre este índice y los niveles de enriquecimiento de nutrientes en agrosistemas intensamente fertilizados, con mayor producción radical que en un sistema natural (Bongers, 1990). Los suelos del sitio 6, presentaron el mayor valor promedio de PPI, coincidiendo con suelos fertilizados durante tres años con una dosis mayor de nitrógeno de la que recibió anteriormente y con agregado de herbicidas. En condiciones de alta disponibilidad de nutrientes, el PPI tiende a ser más alto y el índice IM tiende a ser más bajo (Bongers et al., 1997) situación que se refleja en la relación PPI/IM propuesta por estos autores. La relación PPI/IM de 0,89 en el S7 indicaría que las plantas utilizan los nutrientes en forma óptima; valores hasta 1,2 como en el G3 (PPI/IM= 1,13) pueden ser interpretados como disturbios leves debido al aporte de nutrientes y valores mayores a 1,2 señalaría un exceso de nutrientes como se refleja en el S6 (PPI/IM = 1,45).

\section{CONCLUSIÓN}

De acuerdo a los resultados obtenidos en esta investigación, los sitios presentaron un patrón de agrupamiento diferente en función al porcentaje de grupos tróficos y a los índices de la comunidad de nemátodos. La interpretación conjunta provee información complementaria para evaluar algunas prácticas de manejo tales como fertilización, labranza y uso de herbicidas e inferir sobre la condición nutricional y salud del suelo en huertos frutícolas.

\section{AGRADECIMIENTO}

Este estudio fue financiado por la Secretaría de Investigación de la Universidad Nacional del Comahue.

\section{BIBLIOGRAFÍA}

ARUANI, C.; SÁNCHEZ, E.; DUSSI, C.; ARJONA, C. 2001. Micronutrientes disponibles en suelos del Alto Valle de Río Negro en Argentina. AgroCiencias 17(1): 23-28.

BERKELMANS, R.; FERRIS, H.; TENUTA, M.; VAN BRUGGEN, A.H.C. 2003. Effects of long-term crop management on nematode trophic levels other than plant feeders disappear after 1 year of disruptive soil management. Appl. Soil Ecol. 23: 223-235

BONGERS, T. 1990. The maturity index: an ecological measure of environmental disturbance based on nematode species composition. Oecologia 83: 14-19.

BONGERS, T. 1999. The maturity index, the evolution of nematode life history traits, adaptative radiation and cp-scaling. Plant Soil 212: 13-22.

BONGERS, T.; BONGERS, M. 1998. Functional diversity of nematodes. Appl. Soil Ecol. 10: 239-251.

BONGERS, T.; VAN DER MEULEN, H.; KORTHALS, G. 1997. Inverse relationship between the nematode maturity index and plant parasite index under enriched nutrient conditions. Appl. Soil Ecol. 6: 195-199.

CAVENESS, F.E.; JENSEN, H.J. 1955. Modification of the centrifugal-flotation technique for the isolation and concentration of nematodes and their eggs from soil and plant tissue. Proceedings of the Helminthological Society of Washington 22: 87-89.

CIL (CONSORCIO INCONAS LATINOCONSULT S.A). 1991. Estudio para el aprovechamiento integral del Río Negro. Argentina. Etapa II. Informe Edafológico, Buenos Aires, Argentina, 243 p.

DI RIENZO, JA.; CASANOVES, F.; BALZARINI, M.G.; GONZALEZ, L.; TABLADA, M.; ROBLEDO, C.W. 2009. InfoStat versión 2009. Grupo InfoStat, FCA, Universidad Nacional de Córdoba, Argentina.

DONG, D.; CHEN, Y.; STEINBERGER, Y.; CAO, Z-P. 2008. Effects of different soil management practices on soil free-living nematode community structure, Eastern China. Canadian Journal of Soil Science 88:115-127.

FAO 2006. Evapotranspiración del cultivo. Guías para la determinación de los requerimientos de agua de los cultivos. Alle, R.; Pereira, L.; Raes D.; Smith M. Estudio FAO de Riego y Drenaje $n^{\circ} 56$.

FERRIS, H. 2010. Contribution of Nematodes to the 
Structure and Function of the Soil Food Web. J. Nematol. 42(1):63-67.

FERRIS, H.; BONGERS, T.; DE GOEDE, R.G.M. 2001. A framework for soil food web diagnostics: extension of the nematode faunal analysis concept. Appl. Soil Ecol. 18: 13-29.

FERRIS, H.; VENETTE, R.C.; LAU, S.S. 1996. Dynamics of nematode communities in tomatoes grown in conventional and organic farming systems, and their impact on soil fertility. Appl. Soil Ecol. 3:161-175.

FERRIS, H.; VENETTE, R.C.; SCOWC, K.M. 2004. Soil management to enhance bacterivore and fungivore nematode populations and their nitrogen mineralization function. Appl. Soil Ecol. 25: 19-35.

FRECKMAN, D.W.;ETTEMA, C.H. 1993.Assessing nematode communities in agroecosystems of varying human intervention. Agric. Ecosyst. Environ. 45: 239-261.

GRUZDEVA, L.; MATVEEVA, E.; KOVALENKO, T. 2007. Changes in soil nematode communities under the impact of fertilizers. Eurasian Soil Biology_40 (6): 681-693.

HENDRIX, P.F.; PARMELEE, R.W.; CROSSLEY, D.A.; COLEMAN, D.C.; ODUM E.P.; GROFFMAN, P.M. 1986. Detritus food webs in conventional and no tillage agroecosystems. BioScience 36: 374-380.

LENZ, R.; EISENBEIS, G. 2000. Short-term effects of different tillage in a sustainable farming system on nematode community structure. Biology and Fertility of Soils 31: 237-244.

NEHER, D.A. 1999. Nematode communities in organically and conventionally managed agricultural soils. J. Nematol. 31 (2): 142-154.

NEHER, D.A. 2001. Role of nematodes in soil health and their use as indicators. J. Nematol. 33 (4): 161-168.

NEHER, D.A.; OLSON, R.K. 1999. Nematode communities in soils of four farm cropping management systems. Pedobiologia 43: 430-438.

NORTON, D. 1989. Abiotic Soil Factors and Plantparasitic Nematode Communities. J Nematol. 21(3): 299-307.

OKADA, H.; HARADA, H. KADOTA, I. 2005. Fungal-feeding habits of six nematode isolates in the genus Filenchus. Soil Biol. Biochem. 37: 1113-1120.

PORAZINSKA, D.L.; COLEMAN, D.C. 1995. Ecology of nematodes under influence of Cucurbita spp. and different fertilizer types. Supplem. J. Nematol. 27 (4S): 617-623.

SÁNCHEZ, E.E. 1999. Nutrición mineral de frutales de pepita y carozo. Instituto Nacional de Tecnología Agropecuaria. Estación Experimental Alto Valle de Río Negro. Río Negro. Argentina.
SÁNCHEZ-MORENO, S.; FERRIS, H. 2007. Suppressive service of the soil food web: Effects of environmental management. Agric. Ecosyst. Environ. 119: 75-87.

SÁNCHEZ-MORENO, S.; MINOSHIMA, M.; FERRIS, H.; JACKSON, L.E. 2006. Linking soil properties and nematode community composition: effects of soil management on soil food webs. Nematology 8 (5): 703-715.

SOIL SURVEY STAFF. 2006. Keys to Soil taxonomy. $10^{\text {th }}$ Edition. USDA. NRCS, Washington DC. 341pp.

UIA, 2008. Debilidades y Desafíos Tecnológicos del Sector Productivo 2008, http://www.uia.org.ar/fla/ debilidades2008/index.html.

VAN ECKEREN, N.; DE BOER, H.; BLOEM, J.; SCHOUTEN, T.; RUTGERS M.; DE GOEDE, R.; BRUSSAARD, L. 2009. Soil biological quality of grassland fertilized with adjusted cattle manure slurries in comparison with organic and inorganic fertilizers. Biol. Fertil. Soils 45: 595-608.

VILLENAVE, C.; SAJ, S; PABLO, A.; SAIL, S.; DJIGAL, D.,; CHOTTE, J.; BONZI, M. 2010. Influence of long-term organic and mineral fertilization on soil nematofauna when growing Sorghum bicolor in Burkina Faso. Biol. Fertil. Soils 46: 659-670.

WANG, R.H.; MCSORLEY, R.; MARSHALL, A.; GALLAHER, R.N. 2006. Influence of organic Crotalaria juncea hay and ammonium nitrate fertilizers on soil nematode communities. Appl. Soil Ecol. 31: 186-198.

WASILEWSKA, L. 1979. The structure and function of soil nematode communities in natural ecosystems and agrocenoses. Polish Ecological Studies 5: 7-145.

WASILEWSKA, L. 1997. Soil invertebrates as bioindicators, with special reference to soil-inhabiting nematodes. Russ J. Nematol. 5 (2): 113-126.

WEINBAUM S.A.; JOHNSON R.S.; DEJONG, T.M. 1992. Causes and consequences of over fertilization in orchards. Hort. Tech. 2:112-121.

YEATES, G.W.; BONGERS, T., 1999. Nematode diversity in agroecosystems. Agric. Ecosyst. Environ. 74: 113-135.

YEATES, G.W.; WARDLE, D.A.; WATSON, R.N. 1999 Responses of soil nematode population community structure, diversity and temporal variability to agricultural intensification over a seven year period. Soil Biology and Biochemistry 31(12): 1721-1733.

YEATES, G.W.; BONGERS, T.; de GOEDE, R.G.M.; FRECKMAN D.W.; GEORGIEVA, S.S. 1993. Feeding habits in soil nematode families and genera - An outline for soil ecologists. J. Nematol. 25: 315-331. 